\title{
Cross Inoculation Tests with Phellinus noxius Isolates from Nine Different Host Plants in the Ryukyu Islands, Southwestern Japan
}

\author{
Norio Sahashi, Mitsuteru Akiba, Makoto Ishihara, and Kazuhiro Miyazaki, Forest Microbiology Research \\ Group, Kyushu Research Center, Forestry and Forest Products Research Institute (FFPRI), Kurokami 4-11-16, Ku- \\ mamoto, 860-0862, Japan; and Natsumi Kanzaki, Laboratory of Forest Pathology, Department of Forest Microbiol- \\ ogy, FFPRI, Matsunosato 1, Tsukuba, 305-8687, Japan
}

\begin{abstract}
Sahashi, N., Akiba, M., Ishihara, M., Miyazaki, K., and Kanzaki, N. 2010. Cross inoculation tests with Phellinus noxius isolates from nine different host plants in the Ryukyu Islands, southwestern Japan. Plant Dis. 94:358-360.

Brown root rot, caused by Phellinus noxius, leads to problems in management of shade, ornamental, and windbreak trees in subtropical regions of the world, and it has been causing serious problems in Japan since 1988. To identify the pathogenicity, host specialization, and virulence of the pathogen, cross inoculation tests were carried out using isolates of the fungus obtained from nine different tree species. P. noxius was pathogenic to all of the nine tree species tested, and it killed inoculated seedlings. Among the 810 trees inoculated with the fungus, a total of 141 trees (17.4\%), including all nine species, were dead within 110 days after inoculation. The first symptom of infection was rapid wilt with discoloration of leaves 20 to 30 days after inoculation, and then the plants quickly declined. Only one isolate of $P$. noxius that was tested caused significantly higher mortality in its original host than in other species, suggesting that the pathogen has little to no host specificity. However, the fungus did show variation in virulence, with the isolates originating in Bischofia javanica and Casuarina equisetifolia causing significantly higher mortality than those collected from other host species. More isolates of $P$. noxius from the same host species and/or from various countries should be studied to understand host specialization and virulence of the pathogen.
\end{abstract}

Phellinus noxius (Corner) G.H. Cunn. is widely distributed in Southeast Asia, the Pacific Islands and Australia, Central America, and Africa $(2,4,5,7,9,12)$. The fungus has a very wide host range (4), and more than 200 woody plant species worldwide have so far been reported as host plants (2). The fungus causes brown root rot in a variety of orchard and forest tree species as well as shade, windbreak, and ornamental or landscape trees, and is one of the most destructive pathogens for these species $(2,3,6,9,14-16)$. Affected trees show reduced growth, yellowing and wilting of leaves, defoliation, and dieback of branches, which are similar to decline symptoms caused by other root rot pathogens. Most affected trees eventually die. Sometimes the fungus causes rapid wilt of

Corresponding author: N. Sahashi

E-mail: sahasi@affrc.go.jp

N. Sahashi and M. Akiba contributed equally to this work.

Current address of N. Sahashi and M. Akiba: Laboratory of Forest Pathology, Department of Forest Microbiology, FFPRI, Matsunosato 1, Tsukuba, 305-8687, Japan.

Accepted for publication 24 November 2009.

doi:10.1094/PDIS-94-3-0358

(C) 2010 The American Phytopathological Society trees with discoloration of leaves followed by death within a few months (quick decline) $(2,7,9)$

In Japan, brown root rot was first found in windbreaks on Ishigaki Island of Okinawa Prefecture in 1988 (1). Since then, the disease has been reported on several islands of both Okinawa and Kagoshima prefectures, and it has been causing serious problems for several tree species in subtropical regions of southern Japan $(8,10,11,18)$.

There is some information published on the pathogenicity and virulence of $P$. noxius $(1,3,4,6,13,15)$. In Taiwan, Chang (6) carried out cross pathogenicity tests in which $P$. noxius isolates from 12 different host species were used to inoculate all others and concluded that the fungus had a wide host range and no apparent host specificity. Ann et al. (3) reported similar results for nine $P$. noxius isolates from different fruit tree hosts. However, most host species reported from Japan have not been proven experimentally to be susceptible to $P$. noxius because of the lack of pathogenicity tests, and no information on host specialization or virulence is available; these have been referred to as host plants of $P$. noxius without completion of Koch's postulates.

Clarifying host specialization or variation in virulence among isolates of the fungus is an important step for understand- ing the biology and ecology, and for developing efficient procedures for controlling the disease. This study was undertaken to investigate pathogenicity, host specialization, and virulence of $P$. noxius isolates to plants of nine woody species important to Japan.

\section{MATERIALS AND METHODS}

Source of $P$. noxius isolates and inoculum preparation. Isolates of $P$. noxius used in this study had been collected over a 10 -year period from declining or dead adult trees of nine different tree species in subtropical regions of Japan (Table 1) according to the method of Sahashi et al. (18). These trees included species important as windbreaks and ornamental landscape plantings, and those seemed to be relatively susceptible to the fungus based on previous field observations $(11,18)$. Isolates of $P$. noxius were grown on a sawdust medium (beech sawdust:rice bran: water $=24: 6: 11, \mathrm{vol} / \mathrm{vol} / \mathrm{vol}$ ) in plastic bottles at room temperature (ca. $25^{\circ} \mathrm{C}$ ) for approximately 2 months.

Preparation and inoculation of test trees. Plants (ca. $70 \mathrm{~cm} \mathrm{high)} \mathrm{of} \mathrm{each} \mathrm{of}$ the nine test tree species were transplanted individually into pots $(18 \mathrm{~cm}$ diameter) to accelerate new root growth, 2 months before the fungal inoculation. We used 3year-old plants except for Bischofia javanica Blume (1 year old). These plants were grown under the cover of black cheesecloth in the nursery of the Kyushu Research Center, FFPRI in Kumamoto City, and were irrigated twice a day with tap water using a sprinkler system. Plants were inoculated in all possible combinations with an isolate from each of the nine different host species. The tap root $(3 \mathrm{~cm}$ under the soil surface) of each plant was exposed, and the entire bark was removed at two positions with a sterile knife (approximately $1.5 \times 0.5 \mathrm{~cm}$ ). About $80 \mathrm{~g}$ of sawdust culture of the fungus was placed on the injured tap root and covered with soil. Ten seedlings were used for each fungal isolate-host species combination. Ten plants of each tree species similarly inoculated with sterile sawdust medium were used as controls. The incidence of seedlings killed was expressed as a percentage of total seedlings inoculated, 110 days after inoculation. At the end of the experiments, reisolation of $P$. noxius from 
diseased roots of dead trees was conducted as described elsewhere (18).

Statistical analysis. All data were analyzed with Statview 4.0 for Macintosh. Host specificity of each isolate was examined using chi-square test to compare the percent mortality of the original host species with the average mortality of all nine tree species caused by each corresponding isolate. Prior to comparisons of the virulence of fungal isolates and the susceptibility/resistance of tree species, mortalities were converted into virulence or susceptibility/resistance indices based on the average of each treatment to standardize values among treatments; virulence indices were calculated by subtracting the average mortality of each host from the mortalities in respective treatments (same row), and susceptibility/resistance indices were done by subtracting the average mortality caused by each fungal isolate from the mortalities in respective treatments (same column) (Table 2). The indices were analyzed using one-way analysis of variance (ANOVA) and compared with Fisher's PLSD post hoc test among fungal isolates (virulence) and among tree species (susceptibility/resistance).

\section{RESULTS}

$P$. noxius pathogenicity and disease symptoms. $P$. noxius was pathogenic to all nine tree species tested, and all species experienced some mortality. Among the 810 trees inoculated with the fungus, a total of 141 trees (17.4\%) across all nine species were dead within 110 days after inoculation (Table 2). The first visible disease symptoms were observed 20 to 30 days after inoculation (Fig. 1), and included rapid wilt with a change of leaf color from dark to pale green. All affected trees declined quickly. Disease symptoms were especially severe in trees of the following five species: Machilus thunbergii Sieb. et Zucc., Rhaphiolepis indica (L.) Lindl. ex Ker var. umbellata (Thunb. ex Murray) Ohashi, Casuarina equisetifolia Forster, Cinnamomum japonicum Sieb. ex Nakai, and Melia azedarach L. var. subtripinnata Miq. Mortality was observed in all tree species 110 days after inoculation and was quite variable with averages ranging from $8.9 \%$ in Calophyllum inophyllum L. to $30.0 \%$ in $R$. indica var. umbellata (Table 2). Podocarpus macrophyllus (Thunb.) D. Don, with $27.8 \%$ average mortality, was also more susceptible than two other species, C. inophyllum and Garcinia subelliptica Merr. (Fisher's PLSD test, $\alpha=0.05)$. All control plants remained healthy during the experiment.

At the time of death, tissues of roots became soft with zone lines, and adhering to roots was a layer of brown fungal mycelia

Table 1. Host plants and isolates of Phellinus noxius used for cross inoculation tests

\begin{tabular}{llll}
\hline Host plant (source of isolate) & Isolate & Collection site & Common usage of host \\
\hline Bischofia javanica & KPN100 & Kikaijima Is., Kagoshima Pref. & Ornamental landscape planting \\
Calophyllum inophyllum & KPN81 & Ishigaki Is., Okinawa Pref. & Windbreak, Hedge, Ornamental landscape planting \\
Casuarina equisetifolia & KPN92 & Kikaijima Is., Kagoshima Pref. & Windbreak \\
Cinnamomum japonicum & KPN89 & Tokunosihima Is., Kagoshima Pref. & Garden tree, Ornamental landscape planting \\
Garcinia subelliptica & KPN78 & Ishigaki Is., Okinawa Pref. & Windbreak, Ornamental landscape planting \\
Machilus thunbergii & KPN54 & Amani-Ohshima Is., Kagoshima Pref. & Ornamental landscape planting \\
Melia azedarach var. subtripinnata & KPN83 & Iriomote Is., Okinawa Pref. & Ornamental landscape planting, Garden tree \\
Podocarpus macrophyllus & KPN77 & Ishigaki Is., Okinawa Pref. & Windbreak, Hedge, Ornamental landscape planting \\
Rhaphiolepis indica var. umbellata & KPN85 & Tokunosihima Is., Kagoshima Pref. & Windbreak, Hedge, Dyeing material \\
\hline
\end{tabular}

Table 2. Mortality results for nine different host species inoculated with nine different isolates of Phellinus noxius

\begin{tabular}{|c|c|c|c|c|c|c|c|c|c|c|}
\hline \multirow[b]{2}{*}{ Host plant species } & \multicolumn{10}{|c|}{ Isolate used and percentage of seedling killed } \\
\hline & KPN100 & KPN81 & KPN92 & KPN89 & KPN78 & KPN54 & KPN83 & KPN77 & KPN85 & Average $^{y}$ \\
\hline Bischofia javanica & $30^{\mathrm{w}}$ & 30 & 10 & 40 & 10 & 0 & 0 & 0 & 0 & $13.3 \mathrm{bc}$ \\
\hline Calophyllum inophyllum & 40 & $10^{\mathrm{w}}$ & 10 & 0 & 10 & 0 & 10 & 0 & 0 & $8.9 \mathrm{c}$ \\
\hline Casuarina equisetifolia & 50 & 0 & $50^{w}$ & 0 & 20 & 0 & 10 & 0 & 20 & $16.7 \mathrm{abc}$ \\
\hline Cinnamomum japonicum & 70 & 20 & 0 & $0^{\mathrm{w}}$ & 30 & 0 & 20 & 0 & 0 & $15.6 \mathrm{abc}$ \\
\hline Garcinia subelliptica & 50 & 10 & 0 & 0 & $20^{\mathrm{w}}$ & 0 & 10 & 0 & 10 & $11.1 \mathrm{c}$ \\
\hline Machilus thunbergii & 30 & 0 & 70 & 30 & 10 & $0^{\mathrm{w}}$ & 10 & 0 & 0 & $16.7 \mathrm{abc}$ \\
\hline Melia azedarach var. subtripinnata & 50 & 20 & 40 & 20 & 0 & 0 & $10^{\mathrm{w}}$ & 10 & 0 & $16.7 \mathrm{abc}$ \\
\hline Podocarpus macrophyllus & 50 & 60 & 80 & 0 & 10 & 0 & 20 & $0^{\mathrm{w}}$ & 30 & $27.8 \mathrm{ab}$ \\
\hline Rhaphiolepis indica var. umbellata & 30 & 40 & 80 & 0 & 10 & 0 & 50 & 20 & $40^{\mathrm{w}, \mathrm{x}}$ & $30.0 \mathrm{a}$ \\
\hline Average $^{z}$ & $44.4 \mathrm{a}$ & $21.1 \mathrm{~b}$ & $37.8 \mathrm{a}$ & $10.0 \mathrm{bc}$ & $13.3 \mathrm{bc}$ & $0 \mathrm{c}$ & $15.6 \mathrm{bc}$ & $3.3 \mathrm{c}$ & $11.1 \mathrm{bc}$ & \\
\hline
\end{tabular}

${ }^{\text {w }}$ Isolate of $P$. noxius inoculated onto its source plant species.

x Significantly higher than the average mortality by the isolate (chi-square test, $P=0.004)$.

y Means followed by the same letter in a column are not significantly different (Fisher's PLSD test, $\alpha=0.05$ ).

${ }^{\mathrm{z}}$ Means followed by the same letter in a row are not significantly different (Fisher's PLSD test, $\alpha=0.05$ ).
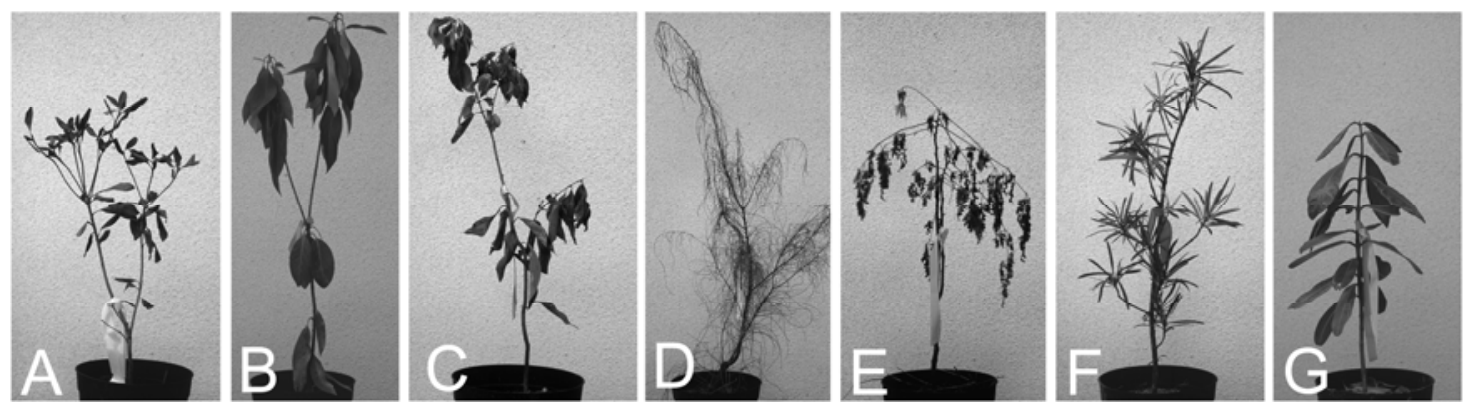

Fig. 1. Rapid wilt and leaf discoloration in trees infected with Phellinus noxius 30 days after inoculation. A, Rhaphiolepis indica var. umbellata; B, Machilus thunbergii; C, Cinnamomum japonicum; D, Casuarina equisetifolia; E, Melia azedarach var. subtripinnata; F, Podocarpus macrophyllus; G, Calophyllum inophyllum. 


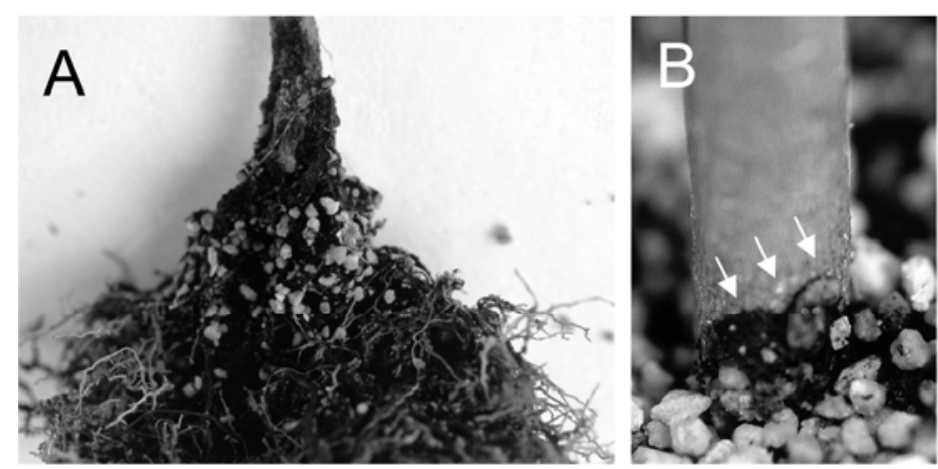

Fig. 2. Root symptoms of trees infected with Phellinus noxius. A, dark brown mycelial mat with embedded soil particles on the root system; $\mathbf{B}$, brown mycelial crust that has developed up to stem base (arrows).

mixed with soil particles (Fig. 2A). Sometimes, a dark brown to black mycelial crust of the fungus developed up to the base of the stem (Fig. 2B). The same fungus was successfully reisolated from diseased roots of artificially inoculated trees.

Host specificity and virulence. Only one of the $P$. noxius isolates (KPN85) that was tested caused significantly higher mortality $(P=0.004)$ in its source host tree species $(R$. indica var. umbellata) than it did in other trees $(P>0.05$, Table 2). However, the virulence of $P$. noxius isolates did vary, with percent mortalities ranging from 0 to $44.4 \%$. Isolates $\mathrm{KPN} 100$ and KPN92, originating from B. javanica and $C$. equisetifolia, caused significantly higher mortality than the other seven isolates (Fisher's PLSD test, $\alpha=0.05$ ) and killed trees from nine and seven of the tree species tested, respectively. Isolate KPN54, originating from $M$. thunbergii, did not cause mortality in any of the nine tree species, although some plants inoculated with this isolate showed slight fading of foliage, and when sampled, their roots were covered with a sparse mycelial mat around the inoculation site.

\section{DISCUSSION}

Since 1988, when brown root rot was first reported in Japan (1), a variety of tree species have been reported as host plants of $P$. noxius based on the symptoms in naturally infected plants and isolation of the fungus from these plants $(8,10,11,18)$. However, few of the previously reported host species occurring in Japan and elsewhere have been proven experimentally to be susceptible to $P$. noxius using inoculation tests and the completion of Koch's postulates. In the present study, we demonstrated clearly that $P$. noxius is pathogenic and able to kill all of the nine tree species tested. Disease symptoms of artificially inoculated trees were similar to those occurring in naturally infected trees $(2,9,18)$.

All isolates of $P$. noxius except for one, KPN54 from $M$. thunbergii, which did not cause mortality in any trees, had a broad host range and caused infection and mor- tality in several tree species. It remains unclear why the $M$. thunbergii isolate did not cause mortality, but the long-term storage under laboratory conditions of the isolate compared with the others might have affected its pathogenicity. Only one isolate caused significantly higher mortality in its original host compared with other trees, suggesting that the pathogen is generally not host specialized. These results were consistent with the findings in previous reports from Taiwan $(3,6)$ in which several $P$. noxius isolates from different hosts were used to inoculate each of the host species.

There have been some reports about the virulence of $P$. noxius. Nandris et al. (15) and Nicole et al. (17) reported that variability in virulence or pathogenicity to Hevea brasiliensis (Willd. ex Adr. de Juss) Muell. Arg. seedlings was found among isolates of $P$. noxius from West Africa. However, other reports suggest no apparent difference in virulence among $P$. noxius isolates from different host plants $(3,6)$. In the present study, percentages of tree species killed by different isolates were quite variable (0 to $44.0 \%)$, and KPN100 (B. javanica isolate) and KPN92 (C. equisetifolia isolate) caused significantly higher mortality than the other isolates. These results strongly suggest that $P$. noxius isolates vary in virulence as pointed out by Nandris et al. (15) and Nicole et al. (17). However, these results were different from those reported by Chang (6) and Ann et al. (3). This discrepancy may have been due to differences in inoculation procedures and/or other factors such as soil and temperature conditions.

In the present study, only one isolate from each host species was available. Therefore, more isolates from the same hosts should be studied to clarify the virulence and host specialization in $P$. noxius. Furthermore, physiological characteristics of the fungus as well as histopathological and/or biochemical aspects at the early stage of infection should be studied, which will lead to a better understanding of hostparasite interaction in this disease system.

\section{ACKNOWLEDGMENTS}

We thank S. Seki, Y. Fukushima, and N. Kawachi, Kyushu Research Center, FFPRI for their help throughout the experiment. Thanks are also due to Y. Abe, and T. Hattori of Nihon University and Kansai Research Center, FFPRI, respectively, for their valuable suggestions and comments.

\section{LITERATURE CITED}

1. Abe, Y., Kobayashi, T., Ohnuki, M., Hattori, T., and Tsurumachi, M. 1995. Brown root rot of trees caused by Phellinus noxius in windbreaks on Ishigaki Island, Japan - Incidence of disease, pathogen, and artificial inoculation. Ann. Phytopathol. Soc. Jpn. 61:425-433.

2. Ann, P.-J., Chang, T.-T., and Ko, W.-H. 2002. Phellinus noxius brown root rot of fruit and ornamental trees in Taiwan. Plant Dis. 86:820826.

3. Ann, P. J., Lee, H. L., and Huang, T. C. 1999 Brown root rot of 10 species of fruit trees caused by Phellinus noxius in Taiwan. Plant Dis. 83:746-750.

4. Bolland, L. 1984. Phellinus noxius: Cause of a significant root-rot in Queensland hoop pine plantations. Aust. For. 47:2-10.

5. CABI/EPPO. 1997. Phellinus noxius. Distribution maps of plant diseases, No. 104. CAB International, Wallingford, UK.

6. Chang, T.-T. 1995. Decline of nine tree species associated with brown root rot caused by Phellinus noxius in Taiwan. Plant Dis. 79:962-965.

7. Chang, T. T., and Yang, W. W. 1998. Phellinus noxius in Taiwan: Distribution, host plants and the $\mathrm{pH}$ and texture of rhizosphere soils of infected hosts. Mycol. Res. 102:1085-1088.

8. Hattori, T., Abe, Y., and Usugi, T. 1996. Distribution of clones of Phellinus noxius in a windbreak on Ishigaki Island. Eur. J. For. Pathol. 26:69-80.

9. Hodges, C. S., and Tenorio, J. A. 1984. Root disease of Delonix regia and associated tree species in the Mariana Islands caused by Phellinus noxius. Plant Dis. 68:334-336.

10. Kawabe, Y., Kobayashi, T., and Usugi, T. 1993. Brown root rot of woody plants caused by Phellinus noxius in Okinawa Prefecture. (In Japanese.) For. Pests 42:176-179.

11. Kobayashi, T., Abe, Y., and Kawabe, Y. 1991 Brown root rot disease: A new threat found in windbreaks in Okinawa Prefecture, Japan. (In Japanese.) Forestry Chem. 118:1-7.

12. Larsen, M. J., and Cobb-Poulle, L. A. 1990. Phellinus (Hymenochaetaceae). A survey of the world taxa. Synopsis Fungorum 3. Fungiflora, Oslo, Norway.

13. Mohd Farid, A., Maziah, Z., Ab. Rasip, A. G., and Noraini Sikin, Y. 2001. Preliminary study on pathogenicity of three root disease fungi on Azadirachta excelsa (Sentang). J. Trop. For. Sci. 13:554-558.

14. Nandris, D., Nicole, M., and Geiger, J. P. 1987. Root rot diseases of rubber trees. Plant Dis. 71:298-306.

15. Nandris, D., Nicole, M., and Geiger, J. P. 1987. Variation in virulence among Rigidoporus lignosus and Phellinus noxius isolates from West Africa. Eur. J. For. Pathol. 17:271-281

16. Neil, P. E. 1986. A preliminary note on Phellinus noxius root rot of Cordia alliodora plantings in Vanuatu. Eur. J. For. Pathol. 16:274280.

17. Nicole, M., Nandoris, D., Geiger, J. P., and Rio, B. 1985. Variability among African populations of Rigidoporus lignosus and Phellinus noxius. Eur. J. For. Pathol. 15:293-300.

18. Sahashi, N., Akiba, M., Ishihara, M., Abe, Y., and Morita, S. 2007. First report of the brown root rot disease caused by Phellinus noxius, its distribution and newly recorded host plants in the Amani Islands, southern Japan. For. Pathol. 37:167-173. 